Final version published as: Stiles, W.B., Hill, C.E., \& Elliott, R. (2015). Looking both ways, Psychotherapy Research, 25, 282-293, DOI: 10.1080/10503307.2014.981681. This is an author final version and may not exactly replicate the final version. It is not the copy of record.

\author{
Looking Both Ways \\ William B. Stiles, Miami University and Appalachian State University \\ Clara E. Hill, University of Maryland \\ Robert Elliott, University of Strathclyde
}

Prepared for the 25th anniversary of Psychotherapy Research.

Correspondence:

William B. Stiles

P O Box 27

Glendale Springs, NC 28629, USA

Email: stileswb@miamioh.edu

\begin{abstract}
On the occasion of the 25th anniversary of the journal, Psychotherapy Research, three former editors first look back at (a) the controversial persistence of the Dodo verdict (i.e., the observation that all bona fide therapies seem equally effective), (b) the connection between process and outcome, (c) the move toward methodological pluralism, and (d) the politicization of the field around evidence-based practice and treatment guidelines. We then look forward to the next 25 years, suggesting that it would be promising to focus on three areas: (a) systematic theory-building research, (b) renewed attention to fine-grained study of therapist techniques, and (c) politically expedient research on the outcomes of marginalized or emerging therapies.
\end{abstract}




\section{Looking Both Ways}

We appreciate the invitation to comment on the past and future directions of psychotherapy research on the occasion of this journal's 25th anniversary. We begin with the disclaimer that although we have all served as editors for a great number and variety of manuscripts for Psychotherapy Research, the three of us do not by any means represent the journal's range of research and scholarship. The journal has addressed many important topics that we do not consider in this article, and future researchers will be concerned with many topics that we do not feature. We do not here attempt a comprehensive or balanced review of the past and future of psychotherapy research. Instead, the comments that follow represent our personal perspectives, melded a bit by this joint assignment.

The melding was easy, as the three of us have held similar interests and commitments (e.g., generally humanistic therapy orientations; commitment to methodological pluralism). We have also enjoyed intertwined careers, beginning with a symposium at the 1980 American Psychological Association convention organized by Alvin Mahrer $(1980)^{1}$, who invited the three of us to speak to a title that presaged our present assignment: Psychotherapy process research: A preview of the next decade. We each began our careers conducting research in verbal process coding (e.g., Elliott, 1985; Elliott et al., 1987; Hill, 1978; Stiles, 1979) and remain interested in process research and process-outcome relations. Each of us developed mid-career interests in qualitative research, including case study methods (Elliott, 1989; Hill, Thompson, \& Williams, 1997; Stiles, 1993), although we have each also continued using traditional methodologies. And of course, we have all been active in the Society for Psychotherapy Research and served as successive editors of Psychotherapy Research.

In this article, we look both ways as we step into the journal's next quarter century. First we look back at a few major themes and developments that have had a big impact on us and seem to us to have continuing influence on psychotherapy research. Then we look ahead, suggesting three themes that seem particularly promising to us.

\section{Looking Back}

We begin by discussing the enduring paradox of finding equivalent outcomes across diverse treatment orientations. Next we review some efforts to study the relationship between process and outcome. Third, we note some changes in methodologies over the past 25 years. And to close this section, we discuss the increasing politicization of psychotherapy research.

\section{The Equivalence Paradox}

For nearly 80 years, the Dodo verdict--"Everybody [i.e., every bona fide psychotherapeutic approach] has won, and all must have prizes" (Rosenzweig, 1936, p. 412, after Carroll, 1865, p. 34)--has driven a great proportion of psychotherapy research. That is, manifestly nonequivalent therapeutic approaches have tended to produce equivalent positive outcomes. This equivalence paradox has been deeply puzzling to psychotherapy researchers (Elliott, Stiles, \& Shapiro, 1993; Hunsley \& Di Julio, 2002; Luborsky, Singer, \& Luborsky, 1975; Stiles, Shapiro, \& Elliott, 1986; Wampold, 2001). Investigators have repeatedly attempted to challenge one or the other side of the paradox--either the equivalence of the outcomes or the non-equivalence of the process.

According to our reading, outcome research over the past 25 years has continued to suggest that all bona fide therapies are effective (Lambert, 2013; Wampold, 2001), though this conclusion remains controversial (e.g., Clark, Fairburn, \& Wessely, 2008; Stiles, Barkham, Mellor-Clark, \& Connell, 2008), and some reviews identify exceptions (e.g., for phobias and 
panic; Elliott, 2013: Tolin, 2010). How can this remarkable equivalence of outcomes be explained? Are the theoretical differences illusory, distracting us from underlying commonalities in the treatment process (Goldfried, 1980; Norcross, 2011)? Is there some encompassing theoretical explanation (Stiles, Elliott, et al., 1990)? Are the similar outcomes a misleading artifact of insufficiently rigorous comparative outcome research? Have we been too focused on therapist contributions, overlooking the role of the client as active change agent (Bohart \& Tallman, 1999; Stiles \& Sultan, 1979)?

\section{The Relationship between Therapist Techniques and Outcome}

We (e.g., Elliott et al., 1987; Hill, Thames \& Rardin, 1979; Hill et al., 1988; Stiles, Shapiro, \& Firth-Cozens, 1988), along with many others (Orlinsky, Grawe, \& Parks, 1994) spent years examining the influence of therapist techniques on the outcome of psychotherapy. Like many others, we conceptualized techniques at the micro level, as speech acts or verbal response modes, in which sentence or utterance is coded (e.g., as a reflection of feeling or an interpretation). This approach has been a focus of psychotherapy research ever since Rogers began audio recording of sessions (Rogers, 1942a, 1942b). Snyder (1945) and Porter (1943) were among the first to develop systems for such coding. Many others, including the three of us, have developed versions of these systems. Many training programs have used these frameworks to teach therapeutic skills (e.g., Carkhuff, 1969; Hill, 2014; Ivey, 1971).

The micro-level investigations provided good descriptions of therapist behavior, for example in intakes (e.g., Hill, 1978). They also documented substantial technical differences among theoretical approaches that were consistent with the theoretical prescriptions (e.g., Elliott et al., 1987; Hill, Thames \& Rardin, 1979; Stiles, 1979; Stiles, Shapiro, \& Firth-Cozens, 1988). That is, contrary to earlier suppositions, therapists were not all doing the same thing. Despite indications that the process and outcome measures were sound, however, the investigations failed to find convincing or consistent associations of therapist techniques with session impact or with treatment outcome. And, for many researchers, if there is no clear connection between process and outcome, process does not matter.

To illustrate, Hill et al. (1988) examined the associations of the verbal response modes in each therapist speaking turn with client-rated reactions, therapist ratings of helpfulness, client ratings of helpfulness, and judge-rated client experiencing levels in the subsequent client speaking turn. The verbal response modes accounted for only $1 \%$ of the variance of these microoutcome variables. When relevant context variables (therapist intentions and previous client experiencing) were statistically controlled, the variance accounted for dropped to almost nothing. Likewise, none of the correlations between percentages of four theoretically-important therapist verbal response modes (questions, interpretations, general advisements, and exploratory reflections) and four standard outcome measures were significant in Stiles and Shapiro's (1994) examination of cognitive-behavioral therapy and psychodynamic-interpersonal therapy. This lack of significance did not appear to reflect a failure of measurement of process, insofar as the verbal process components were reliably coded, represented theoretically important techniques, and discriminated between treatments in sensible, expected ways. Nor did it reflect a failure of measurement of outcome, insofar as the outcome measures were standard, widely-used measures that detected large, clinically and statistically significant changes in these treatments.

Techniques can also be assessed more globally at the session level, for example, by listening to an entire session and estimating how much the therapist used interpretations. Three widely-used session-level measures are the Multitheoretical List of Therapeutic Interventions 
(MULTI, McCarthy \& Barbaer, 2009), the Psychotherapy Q-Set (Jones \& Pulos, 1993), and the Comparative Psychotherapy Process Scale (CPPS, Hilsenroth, Blagys, Ackerman, Bonge, \& Blais, 2005). However, Heaton, Hill, and Edwards (1995) found minimal concordance of such global ratings with micro-level coding.

Some reconsideration suggested the problem was not in the micro-level measurement, however, but in the conceptualization of the problem and the statistical model. The equivalent outcomes of alternative treatments may reflect therapists monitoring therapeutic progress and optimizing outcomes by responsively adjusting their approach to client requirements and emerging situations. Such responsiveness directly defeats linear statistical links between process components and outcome measures (Stiles, Honos-Webb, \& Surko, 1998). Ideally, to the extent that therapists are appropriately responsive, the quantity of each technique will vary with client requirements. However, it will not vary with outcomes if all clients receive as much as they require or can use. That is, to the extent therapists are appropriately responsive, even crucially important specific techniques (e.g., interpretation, reflection, assigning homework, Socratic questioning) should show no systematic statistical association with outcomes.

Although responsiveness defeats the ability to find consistent correlations of technical process components with outcome, the same is not necessarily the case with correlations between evaluative process measures and outcome. By evaluative process measures, we refer to such things as alliance and alliance repair, empathy, warmth, and genuineness (e.g., see reviews in Norcross, 2011; Safran \& Muran, 2000). These qualities are not techniques, but rather achievements that reflect therapists doing the right thing at the right time. In effect, evaluations of relationship qualities assess appropriate responsiveness (Stiles et al., 1998).

\section{Methodological Pluralism}

Another major development over the last 25 years has been the shift toward methodological pluralism. For one thing, the field has begun to welcome qualitative methods (e.g., Frommer, Langenbach, \& Streeck, 2004; Hill, 2012; Rennie, 2004), including qualitative meta-analysis (e.g., Timulak, 2007). Qualitative approaches allow researchers to investigate phenomena that occur infrequently (e.g., intense weeping), that are very complex and contextually-dependent (e.g., insight), or that reflect inner experiences not reliably observable to external judges. There has also been a renaissance of systematic case study research, using a variety of new approaches, many with mixed methods, such as pragmatic case studies (Fishman, 1999), consensual qualitative research-case studies (Hill, 2012; Hill et al., 2008), theory-building case studies (Stiles, 2009), and hermeneutic single case efficacy designs (Elliott et al., 2009). In parallel, there has been much growth in sophisticated quantitative methods such as structural equation modeling, generalizability theory, multi-level modeling, and item response theory for data analyses involving very large samples (Doucette \& Wolf, 2009; Kenny \& Hoyt, 2009; Wasserman, Levy \& Loken, 2009).

\section{The Politicization of Psychotherapy Research}

The last 25 years has seen an intense competition for prizes in which the contest involves the accumulation of ever-larger and more complex randomized controlled trials (RCTs). There have been huge increases in the number of RCTs (Imel, Steyvers, \& Atkins, in press), accompanied by the development of an ideology variously described as empirically validated treatment, empirically-supported treatment, or evidence-based practice. Although this ideology has been controversial within psychotherapy research from the beginning (e.g., Elliott, 1998; 
Haaga \& Stiles, 2000), it has become more strident as the field has become more politicized. Increasingly sophisticated and resource-intensive approaches have been brought to bear on comparative psychotherapy outcome research, as reviewers insist on such things as mapping studies by CONSORT case flow charts and random assignment for dealing with potential confounding variables (e.g., Nezu \& Nezu, 2008; Torgerson \& Torgerson, 2008). Similarly, quantitative meta-analysis requirements of ever greater complexity and stringency have emerged for summarizing trial results, including new statistics and careful tracking of studies reviewed and reasons for exclusion (PRISMA reporting; Moher et al., 2009).

One effect has been that, despite the evidence for equivalence among treatments, nonequivalence has been increasingly enshrined in treatment guidelines in multiple countries in the form of lists of treatments that have reached criteria for the number and quality of RCTs (e.g., Society for Clinical Psychology, 2014; National Collaborating Centre for Mental Health, 2009). The lists are sometimes used to confer legitimacy on the listed treatments and, by implication, lack of legitimacy on treatments left off the list. There have also been efforts to label or even ban supposedly harmful or invalid treatments (National Collaborating Centre for Mental Health, 2010; Lilienfeld, 2007).

Advocates of an approach, who have personal and economic interests in ensuring that their approach is sufficiently researched to be added to lists of approved treatments, have an understandable desire to prove that their approach is better than others. Wittingly or unwittingly, they may introduce distortions in the designing, reporting, and interpreting of outcome research. The distortions may reflect an incomplete appreciation of the complexity or subtlety of the opposing comparison approach, leading to a less careful implementation of the comparison approaches in RCTs. Researcher allegiance effects (i.e., finding support for one's favored treatment over comparison treatments) represent one of the best-established findings in psychotherapy research (Elliott, Watson, Greenberg, Timulak \& Freire, 2013; Luborsky et al., 1999, 2002; Robinson, Berman, \& Neimeyer, 1990).

Typically, when researcher allegiance effects are controlled, differences between active treatments disappear. For example, in a recent meta-analysis of roughly 200 humanisticexperiential psychotherapy outcome studies, Elliott, et al. (2013) observed that many nonhumanistic researchers were devising their own versions of humanistic therapies to use as comparison treatments. They then conducted studies and found that these ad hoc humanistic treatments tended to have worse outcomes than the CBT treatments. Spielmans, Pasek, and McFall (2007) noted that the ad hoc therapies differed from bona fide versions of humanistic therapies in that they were significantly shorter, lacked a convincing rationale, and often constrained therapists from using key techniques (e.g., exploring traumatic experiences). Metaanalyses showed that outcomes of bona fide person-centered therapy (PCT) were statistically equivalent to outcomes of CBT (Elliott et al., 2013).

Being excluded from the lists of approved therapies has had serious economic consequences for some practitioners in places like Germany and the United Kingdom (e.g., Hofmeister, 2010). For example, the current guideline on depression from the National Institute for Clinical Excellence (a standard-setting body for England and Wales), based on its own literature review, stated that clients should be offered person-centered therapy only if the client refused five other recommended treatments and then only if the client is warned about the lack of evidence for its effectiveness (National Collaborating Centre for Mental Health, 2009). Similarly, the 2010 guideline on schizophrenia (National Collaborating Centre for Mental Health, 2010) contained a warning against offering supportive therapy or humanistic counseling 
at all (Elliott et al., 2013)! This warning has effectively banned the use of person-centered therapy for clients with psychotic processes in England and Wales.

\section{Looking Ahead}

We suggest three areas for future researchers to pursue. The first suggestion involves using a theory-building process characteristic of normal science to construct explanations of the rich, interactive, context-dependent nature of psychotherapy. The second is returning to the study of therapist within-session behaviors, drawing on more sophisticated concepts and research tools. The third sketches a strategy for confronting the practical, economic, and political institutionalization of empirically-supported treatments by offering new ways to investigate lesswell-known treatment approaches.

\section{Theory-Building Research}

Theory-building research (Stiles, 2009, in press) seeks to test, improve, and extend a particular theory. It is an extension of the way Kuhn (1970) described research conducted in normal science, that is, a mature science that has a paradigm. A paradigm, in Kuhn's sense, is a generally accepted theory together with a body of cardinal examples, practices, and problems to be addressed, shared within a community of researchers. Examples of paradigms include plate tectonics in geology, the standard model in physics, and the Darwinian theory of natural selection in evolutionary biology. Observations are interpreted within the paradigm and are used to refine and elaborate it. Particular studies are typically directed towards solving puzzles, checking specific derivations of the theory against observations, and modifying the theory in light of unexpected observations or discrepancies (while respecting previous observations) or extending the theory into new areas.

Psychotherapy research does not have a generally accepted paradigm in Kuhn's (1970) sense, but there are plenty of candidates, that is, explanatory theories with associated cardinal examples, practices, and problems that can be addressed in research. We suggest that the theorybuilding strategy that works in normal science can be applied within any explanatory theory. Thus, we would encourage psychotherapy researchers to aim toward building an explanatory theory of how psychotherapy works and how it is related to other phenomena.

An explanatory theory synthesizes observations, explaining how observation of one thing indicates that other things have taken place or will take place. The aim of theory-building research is to increase the theory's generality, precision, and realism (Levins, 1968). That is, researchers seek to extend the theory to explain a wider range of phenomena, to specify the theory in greater detail, and to link the theory more clearly and thoroughly to observations.

Theory-building researchers ground their work in the best theory they can find and then use empirical observations (quantitative and qualitative) and their own ingenuity, care, and creativity to solve the puzzles it presents and improve its generality, precision, and realism. The aim is to improve a good explanation by reconciling the existing theory with new observations. The essential element of continually building a particular theory distinguishes theory-building research from research that gathers data and then develops a theory to account for those data (e.g., grounded theory, Rennie, Phillips \& Quartaro, 1988) or from research that only provides a description of what occurs in psychotherapy.

Building explanatory theories involves the logical operations of deduction, induction, and abduction (Stiles, 2009). Deduction is used to ensure the logical coherence of parts of the theory and to logically link the theory to hypotheses and descriptions of observations. Induction is used 
to compare new observations with theoretical expectations, which strengthens (or weakens) confidence in the theory. Abduction refers to modifying the theory to accommodate new observations that diverge from expectations (Rennie, 2000). Abductive reasoning suggests that if a particular modification or extension were part of the theory, then the otherwise divergent observation would be expected. This new capacity to explain justifies tentatively retaining the modification as part of the theory. However, any abductive change must respect previous observations and maintain the theory's internal consistency. A modification or extension to one part of the theory may thus require adjustments in other parts.

Explanatory theories are distinct from treatment theories, which are meant to guide clinicians in conducting therapy. Treatment theories are sometimes based on explanatory theories, and some familiar theories (e.g., psychoanalytic theory, cognitive theory) aspire to be both. The proliferation of treatment theories seems to reflect individual clinicians or groups of clinicians devising techniques on the basis of observations from their clinical experience or on extrapolations from research results. Although treatment theories are sometimes modified in response to research findings, the two types of theory are evaluated by very different criteria. Whereas explanatory theories are evaluated by how general, precise, and realistic they are, treatment theories need not be general, precise, or realistic if they enable therapists to be effective in working with clients. Research on treatment theories takes the form of evaluation, or product-testing studies, such as clinical trials, which assess the acceptability, efficacy, and effectiveness of alternative treatment packages or of particular elements of the change process.

RCTs are designed to test treatment theories rather than explanatory theories. Rather than making observations bearing on the generality, precision, and realism of their new account or reconciling the new observations with an existing explanatory theory, researchers aim to test the effectiveness of the new product by comparing outcomes of their clients with those of clients treated in other ways.

The distinction between theory-building and product-testing research can be illustrated by their different understandings of generality--whether the generality is understood as a property of the theory or as a property of particular findings (Stiles, in press). In theory-building research, the generality is specified by the theory; it is the range of events the theory seeks to explain. In particular theory-building studies, researchers typically examine only small derived facets of the larger theory. Observations consistent with the theory increase confidence in the theory, but the findings themselves are not meant to be generalized. In product-testing research, generality is understood as external validity (Campbell, 1957)--the range of populations and settings in which a treatment can be expected to work or to which that particular finding can be generalized.

In contrast to researchers in fields where there is an accepted paradigm, psychotherapy researchers do not agree on which explanatory theory is worth building. As a result, theorybuilding psychotherapy researchers must accept that their work will be of major interest to only a part of the field. Theory-building research can build on any explanatory theory, however, by investigating its tenets and adjusting the theory in light of observations. To the extent that investigators are flexible and creative, theory-building should yield incremental improvements as more observations are incorporated. The incremental expansion and improvement should gradually yield a more general, precise, realistic theory, which should tend to draw larger audiences.

A study of setbacks in therapy (Caro Gabalda \& Stiles, 2013) illustrates theory-building research on the assimilation model (Stiles, Elliott, et al., 1990), a theory suggesting that progress in psychotherapy follows a regular developmental sequence (Stiles, 2002, 2011). The 
Assimilation of Problematic Experiences Sequence (APES; Stiles, Meshot, Anderson \& Sloan, 1992) characterizes the changing relation of a problematic experience to the self in eight stages: (0) warded off/dissociated, (1) unwanted thoughts/active avoidance, (2) vague awareness/emergence, (3) problem statement/clarification, (4) understanding/insight, (5) application/working through, (6) resourcefulness/problem solution, and (7) integration/mastery. This developmental stage account seemed to describe the sequence of therapeutic progress across treatment (Stiles, 2002), but it seemed contradicted by the clinical observation that, on a smaller scale, therapeutic advances do not proceed in smooth order but rather alternate with setbacks.

To examine this puzzle, transcripts of the complete therapy of two clients were divided into thought units, which were separated into problematic themes and rated using the APES. Setbacks, defined as any return from a higher to a lower APES stage of 1 or larger in adjacent passages (within themes), were classified using a previously developed list of possible alternative reasons for setbacks (Caro Gabalda \& Stiles, 2013).

The results suggested that most setbacks involved subtle topic shifts, from a more assimilated to a less assimilated strand of a problematic experience. The reasons for shifts appeared theoretically and clinically sensible:. In almost all instances, the therapist either had pushed the current strand of the problem to the upper limit of its current therapeutic zone of proximal development (Leiman \& Stiles, 2001) or had strategically directed the client's attention to a less developed strand to balance their progress with attention to more problematic material. Thus, setbacks can be viewed as an integral part of the therapeutic process rather than as disruptions, regressions, or haphazard fluctuations. Incorporating the idea that problematic experiences have distinct strands is an abduction and helps reconcile assimilation theory's developmental sequence with the clinical observation that therapeutic progress is often irregular.

\section{The Influence of Therapist Behaviors on the Process and Outcome of Psychotherapy}

Therapist techniques are at the heart of psychotherapy theory, as therapists act to help clients change. Treatment theories that describe what techniques therapists should use abound. Researchers have tried to describe what therapists do within each approach and to investigate whether and how these techniques bring about change. The disappointing results of our timeintensive process-outcome research (described earlier) challenged our beliefs in the importance of therapist techniques and the value of detailed process research. All three of us abandoned research on verbal response modes (therapist techniques) for a while, partly because of increasing frustration with how to operationalize techniques and how to assess their effects. Reflecting now, however, we think it is time to give therapist techniques another look with different methods. It seems likely that we were using overly simplistic approaches for studying the effects of therapist techniques, and we suggest developing approaches that would allow us to examine their effects in a clinically meaningful way.

Most systems of therapist techniques have a limited number of broad categories, which is important for research because that allows researchers to have enough data within each category to do analyses. Restricting attention to a few types of interventions overlooks the richness and specificity of what therapists are doing. For example, self-disclosures are often coded as one type of intervention, and yet recent research has shown that there are disclosures of similarity, feelings, insight, immediacy, and strategies, all of which are used in different ways and have different consequences (Hill et al., 2014; Pinto-Coelho \& Hill, 2014).

Furthermore, it is important to recognize that therapists do not offer techniques in a vacuum. Rather, they build up to using particular techniques. For example, In the Hill et al 
(1988) study described above, when context variables were added to the equation, the amount of variance accounted for by techniques dropped to almost nothing. Similarly, Castonguay, Goldfried, Wiser, Raue, and Hayes (1996) found an interaction between the alliance and process. Hill (2005) argued that therapist techniques, client involvement, and the therapeutic relationship are inextricably intertwined. Therapist techniques cannot be helpful without a good therapeutic relationship and an involved client. And then therapists responsively use techniques that seem appropriate at a given moment. The intertwining may be clinically obvious, but it hugely complicates research to assess the effects of therapist techniques.

For example, if a therapist were following the Hill (2014) model, she or he might listen and help the client explore to establish a relationship, then challenge to raise the client's awareness, and then interpret to help the client gain an understanding of deeper dynamics. Once the client has some understanding, the therapist might help the client decide what to do differently in his or her life. But this sequence would vary considerably across clients and therapists, with therapists adjusting what they do to meet the client's emerging needs. And of course, therapists are often unaware of or mistaken about what is going on inside the client's mind, as clients do not reveal everything and therapists' countertransference may distort their understanding. Mistakes are made and need to be repaired, a further process that is probably part of what makes therapy effective (Hill \& Knox, 2009; Safran, Muran, \& Eubanks-Carter, 2011). Research examining any therapist technique needs to take all of these factors into account.

We suggest four paths for future research: case study approaches, conversation analyses, comprehensive process analyses, and more sophisticated process analyses.

Case study approaches. One of the intriguing findings of the Hill et al. (1988) study was that therapist self-disclosures were rated by clients as the most helpful therapist verbal response mode whereas therapists rated it as the least helpful. Interestingly, it comprised less than 1\% of the therapist response modes. Additional analyses (Hill, 1989) showed that the eight therapists disclosed in very different amounts (e.g., one used it frequently, another used it only at termination, another never used it). Furthermore, the disclosures were very different (e.g., some were personal and historical, some were feelings about the therapeutic relationship). If the nature of self-disclosure varies so much across therapists and clients, it seems implausible to expect any simple generalizations about the effects of self-disclosure.

To investigate disclosures concerning the therapeutic relationship, also called immediacy, Kasper, Hill, and Kivlighan (2008) and Hill et al. (2008) conducted case studies using consensual qualitative research-case (Jackson, Chui, \& Hill, 2012) with therapists who frequently used disclosures and clients who seemed open to immediacy. Building on these two case studies, Hill et al. (2014) examined 16 cases with doctoral student trainees who had been trained in and used immediacy. The results of this series of case studies suggested that immediacy can be divided into four types (negotiation of the tasks and goals of therapy, making covert feelings about the relationship overt, drawing parallels between outside relationships and the therapy relationship, and repairing ruptures). Consistent consequences across the three studies were that immediacy helped therapists and clients negotiate the therapeutic relationship, helped clients express feelings about the therapist/therapy, facilitated a corrective relational experience, and helped clients feel validated and cared for.

This series of studies provides an example for how the effects of techniques can be studied. The lessons are: (a) researchers need to carefully and narrowly define therapist interventions rather than looking globally at the effect of therapist interventions, (b) a case study approach allows researchers to examine how a technique is used within the context of the whole 
case, and (c) replication across cases allows researchers to draw conclusions about general effects.

Conversation analysis. Conversation analysis (Peräkylä, Antaki, Vehviläinen, \& Leudar, 2008; Sutherland, Peräkylä \& Elliott, 2014), or the study of "talk-in-action," provides a welldeveloped, systematic method of qualitative analysis of collections of examples of a particular type of therapeutic process (e.g., interpretation, two chair work) to produce careful, contextuallygrounded descriptions of how clients and therapists successfully accomplish a particular kind of therapeutic work. For example, Sutherland et al (2014) identified specific types of therapist response used to initiate, maintain, and round off the use of two chair enactments of client selfsoothing.

Comprehensive Process Analysis. Comprehensive Process Analysis (Elliott, 1989; Elliott et al., 1994) is a mixed method approach that combines many of the above strategies (including conversation analysis, case study methods and sequential analysis) to unpack the complex contextual and process factors that brought about particular significantly helpful therapy events. Although originally intended for studying significant events identified by their therapeutic impacts (e.g., client insight), the method can just as easily be used to understand particularly helpful instances of a specific type of therapist technique. One example from Elliott (1989) is that one type of client awareness was an unintended consequence of therapist advicegiving: The therapists' advice to engage in self-assertive behavior led clients to anxiously imagine others' reacting negatively to their possible self-assertion; in the process they became more aware of both the need to take better care of self and also how their fear had prevented them from doing so.

More sophisticated quantitative approaches. Sophisticated quantitative approaches can also make important contributions. For example, Cunha et al. (2012) analyzed the association between exploration, insight, and action skills and client innovative moments (IMs) in two initial, two middle, and two final sessions of three good outcome and three poor outcome cases of emotion-focused therapy (EFT) for depression. They used sequential analysis methods and also incorporated outcome and stage of treatment into the analyses. By using sophisticated probability analyses with a small number of techniques, they were able to uncover general trends (e.g., in good more than in poor cases, therapist exploration and insight responses more often preceded action, reflection, and protest IMs in the initial and middle phases of EFT, but more often preceded reconceptualization and performing change IMs in the final phase).

\section{Politically Expedient Research}

As noted earlier, to address the demands of evidence-based practice, proponents of all approaches are pressed to conduct more and better RCTs. Approaches without evidence from RCTs are marginalized and disenfranchised, whereas approaches with a great deal of evidence, such as CBT, are given prominence. This evidence-based ideology favors treatments that are easier to study, because, for example, they involve fewer sessions, can be manualized, can be delivered more efficiently in groups, or have simpler goals (e.g., symptom change rather than personality change). In addition, the rankings on the lists tend to be self-perpetuating, as approaches without evidence from RCTs lack meaningful representation on grant review committees and guideline development groups.

To help these marginalized or emerging psychotherapies (MEPs) make the journey toward credibility, we suggest the following pathway as one way to build research expertise and political savvy as well as to accumulate evidence and improve the therapy itself.

A useful first step in a MEP treatment development pathway is a series of mixed methods systematic single case studies (McLeod, 2010). Such case studies are feasible for even a single, 
committed practitioner. Thanks to the increased recognition of case study research, such studies can be published in journals like Psychotherapy Research, thus providing an initial level of recognition and establishing a precedent for the use of the new therapy (or the application of the old therapy to a new client population). As a further consequence, adherents of the MEP can begin to lose their suspicion of research and take heart that they can conduct research.

In a second step, adherents of the MEP can form Practitioner Research Networks (PRNs; e.g., Castonguay, Barkham, Lutz, \& McAleavey, 2013; Murphy 2013). Some of these PRNs use on-line data collection facilities (see review by Sales \& Alves, 2012), which facilitate the collection of substantial amounts of low-cost uncontrolled practice-based evidence that can be aggregated, analyzed, and published as open clinical trials in some journals (e.g., Vromans \& Schweitzer, 2011). Such studies yield population parameter estimates of typical pre-post client change and can be compared to larger population benchmark data to make tentative inferences about the influence of the MEP on client change. If the results are positive, as the Dodo verdict suggests they are likely to be, adherents of the therapy begin to feel empowered by seeing evidence for their convictions about the effectiveness of their favored but overlooked approach.

As a third step, proponents can conduct small or medium-sized randomized studies, comparing their MEP with waitlist controls or other treatments. This approach requires that proponents develop treatment manuals and adherence measures. As part of the design, they can collect systematic qualitative data to help them better understand the effects and change processes involved. They might form alliances with proponents of more established approaches and seek collaborative grants, or they might convert their PRNs into practice-based randomized studies ("pragmatic trials").

Finally, through a combination of a high-profile studies and political networking, the MEP's proponents can gain invitations to serve on guideline development groups. From such positions, they can influence mental health treatment policy simply by being present, as well as by providing alternative perspectives on the available research evidence.

The development of EFT for social anxiety, albeit by experienced researchers, illustrates at least part of this developmental pathway (Elliott, 2013; MacLeod, Elliott, \& Rodgers, 2012). Anxiety problems have long been considered the domain of CBT, and existing evidence suggests that humanistic-experiential therapies have been less effective for this client population, even when bona fide versions of this approach are used (Elliott, 2013). Researchers at University of Strathclyde began in a rather open-ended way to do research on the use of PCT and EFT with social anxiety. The first step was a series of hermeneutic single case efficacy studies examining cases with both good and poor outcome to evaluate client change and the causal role of these therapies in bringing about change (MacLeod \& Elliott, 2012; MacLeod, Elliott \& Rodgers, 2012; Stephen, Elliott \& MacLeod, 2011). This open-ended project eventually accumulated enough clients to treat it as an open clinical trial (i.e., a stage two study) and generated promising estimates of client change. Finally, researchers began randomly assigning clients to either PCT or EFT, and the study morphed into a small, early third stage pilot RCT (Elliott, 2013), which showed large amounts of pre-post change and a small but statistically significant advantage for EFT over PCT. Although our experience has aspects clearly specific to the British context, variations of it have occurred in the US and other countries.

Further examples of this same process can be found in the recent development of psychodynamic therapies for anxiety problems, as exemplified by the SOPHO-NET study (Leichsenring et al., 2013), which has now accumulated enough evidence for its own metaanalysis (Keefe, McCarthy, Dinger, Zilcha-Mano \& Barber, 2014). 


\section{Summary}

Looking back, we have seen an intransigent Dodo verdict looming over the field, resistant to researchers efforts to overturn it with better outcome research or to find common active ingredients that explain it. In the absence of clear findings of differential effectiveness, we have seen an escalating competition among therapeutic approaches involving the quantity and quality of the studies themselves. Looking forward, we have recommended three complementary themes for future research: systematic explanatory theory and theory development, taking a close look at the therapist's moment-to-moment behavior, and strategically adapting to the competitive politicized context. We are confident that the second quarter century of Psychotherapy Research will record not only these, but many other themes, methods, and theories, as psychotherapy researchers explore the details and the clinical, social, and political context of what makes psychotherapy effective.

\section{References}

Bohart, A.C., \& Tallman, K. (1999). How clients make therapy work: The process of active selfhealing. Washington, D.C.: American Psychological Association.

Campbell, D. T. (1957). Factors relevant to the validity of experiments in social settings. Psychological Bulletin, 54, 297-312. doi: 10.1037/h0040950

Carkhuff, R. R. (1969). Human and helping relations (Vols. 1 \& 2). New York: Holt, Rinehart, \& Winston.

Caro Gabalda, I., \& Stiles, W. B. (2013). Irregular assimilation progress: Reasons for setbacks in the context of linguistic therapy of evaluation. Psychotherapy Research, 23, 35-53. doi: $10.1080 / 10503307.2012 .721938$

Carroll, L. (1865). Alice's adventures in Wonderland. London: MacMillan \& Co.

Castonguay, L., Barkham, M., Lutz, W., \& McAleavey, A. (2013). Practice-oriented research: Approaches and applications. In M. J. Lambert (Ed.), Bergin and Garfield's Handbook of psychotherapy and behavior change (6 ${ }^{\text {th }}$ ed., pp. 85-133). New York: Wiley.

Castonguay, L. G., Goldfried, M. R., Wiser, S. Raue, P. J., \& Hayes, A. M. (1996). Predicting the effect of cognitive therapy for depression: A study of unique and common factors. Journal of Consulting and Clinical Psychology, 64, 497-504.

Clark, D. M., Fairburn, C.G., \& Wessely, S. (2008). Psychological treatment outcomes in routine NHS services: A commentary on Stiles et al. (2007). Psychological Medicine 38, 629634. Published online : 9 October 2007. doi: 10.1017/S0033291707001869.

Cunha, C., Goncalves, M. M., Hill, C. E., Mendes, I., Ribiero, A. P., Angus, L., \& Greenberg, L. S (2012). Therapist interventions and client innovative moments in emotion-focused therapy for depression. Psychotherapy, 49, 536-548. doi: 10.1037/a0028259

Doucette, A., \& Wolf, A.W. (2009). Questioning the measurement precision of psychotherapy research. Psychotherapy Research, 19, 374-389. doi: 10.1080/10503300902894422

Elliott, R. (1985). Helpful and nonhelpful events in brief counseling interviews: An empirical taxonomy. Journal of Counseling Psychology, 32, 307-322. doi: 10.1037/00220167.32.3.307

Elliott, R. (1989). Comprehensive Process Analysis: Understanding the change process in significant therapy events. In M. Packer \& R.B. Addison (Eds.), Entering the circle: Hermeneutic investigation in psychology (pp. 165-184). Albany, NY: SUNY Press.

Elliott, R. (1998). Editor's Introduction: A guide to the empirically supported treatments controversy. Psychotherapy Research, 8, 115-125. doi: 
$10.1080 / 10503309812331332257$

Elliott, R. (2013). Person-Centered-Experiential Psychotherapy for Anxiety Difficulties: Theory, Research and Practice. Person-Centered and Experiential Psychotherapies, 12, 14-30. doi: 10.1080/14779757.2013.767750

Elliott, R., Hill, C. E., Stiles, W. B., Friedlander, M. L., Mahrer, A. R., \& Margison, F. R. (1987). Primary therapist response modes: Comparison of six rating systems. Journal of Consulting and Clinical Psychology, 55, 218-223. doi: 10.1037/0022-006X.55.2.218

Elliott, R., Partyka, R., Wagner, J., Alperin, R. \& Dobrenski. R., Messer, S.B., Watson, J.C. \& Castonguay, L.G. (2009). An Adjudicated Hermeneutic Single-Case Efficacy Design of Experiential Therapy for Panic/Phobia. Psychotherapy Research, 19, 543-557. doi: 10.1080/10503300902905947 [Appendices available at: http://www.informaworld.com/smpp/content $\sim$ content $=\mathrm{a} 914761426 \sim \mathrm{db}=\mathrm{all} \sim \mathrm{tab}=$ multime dia]

Elliott, R., Shapiro, D.A., Firth-Cozens, J., Stiles, W.B., Hardy, G., Llewelyn, S.P, \& Margison, F. (1994). Comprehensive process analysis of insight events in cognitive-behavioral and psychodynamic-interpersonal therapies. Journal of Counseling Psychology, 41, 449-463.

Elliott, R., Stiles, W. B., \& Shapiro, D. A. (1993). "Are some psychotherapies more equivalent than others?" In T. R. Giles (Ed.), Handbook of effective psychotherapy (pp. 455-479). New York: Plenum Press.

Elliott, R., Watson, J., Greenberg, L.S., Timulak, L., \& Freire, E. (2013). Research on humanistic-experiential psychotherapies. In M.J. Lambert (Ed.), Bergin \& Garfield's Handbook of psychotherapy and behavior change (6th ed.) (pp. 495-538). New York: Wiley.

Fishman, D.B. (1999). The case for pragmatic psychology. New York: New York University Press.

Frommer, J., Langenbach, M., \& Streeck, U. (2004). Qualitative psychotherapy research in German-speaking countries. Psychotherapy Research, 14, 57-75. doi:10.1093/ptr/kph004

Goldfried, M. R.(1980). Toward the delineation of therapeutic change principles. American Psychologist, 35, 991-999. doi: 10.1037/0003-066X.35.11.991

Haaga, D.A.F., \& Stiles, W.B. (2000). Randomized clinical trials in psychotherapy research: Methodology, design, and evaluation. In C.R. Snyder \& R.E. Ingram, Handbook of psychological change (pp. 14-39). New York: Wiley.

Heaton, K. J., Hill, C. E., \& Edwards, L. A. (1995). A comparison of three methods of assessing therapist techniques. Psychotherapy Research, 5, 141-152.

Hill, C. E. (1978). Development of a counselor verbal response category system. Journal of Counseling Psychology, 25, 461-468. doi: 10.1037/0022-0167.25.5.461

Hill, C. E. (1989). Therapist techniques and client outcomes: Eight cases of brief psychotherapy. Newbury Park, CA: Sage.

Hill, C. E. (2005). Therapist techniques, client involvement, and the therapeutic relationship: Inextricably intertwined in the therapy process. Psychotherapy: Theory, Research, Practice, Training, 42, 431-442. Review article; invited article. doi: 10.1037/00333204.42.4.431

Hill, C. E. (Ed.) (2012). Consensual qualitative research: A practical resource for investigating social science phenomena. Washington DC: American Psychological Association.

Hill, C. E. (2014). Helping skills: Facilitating exploration, insight, and action ( $\left.4^{\text {th }} \mathrm{ed}\right)$. Washington DC: American Psychological Association. doi: 10.1037/14345-000 
Hill, C. E., Gelso, C. J., Chui, H., Spangler, P., Hummel, A., Huang, T., Jackson, J., Jones, R., Palma, B., Bhatia, A., Gupta, S., Ain, S., Klingaman, B., Lim, R., Liu, J., Hui, K., Jezzi, M., \& Miles, J. R., (2014). To be or not to be immediate with clients: The use and effects of immediacy in psychodynamic/interpersonal psychotherapy. Psychotherapy Research, 24, 299-315. doi: 10.1080/10503307.2013.812262

Hill, C. E., Helms, J. E., Tichenor, V., Spiegel, S. B., O'Grady, K. E., \& Perry, E. S. (1988). The effects of therapist response modes in brief psychotherapy. Journal of Counseling Psychology, 35, 222-233. doi: 10.1037//0022-0167.35.3.222

Hill, C. E., \& Knox, S. (2009). Processing the therapeutic relationship. Psychotherapy Research, 19, 13-29. doi: 10.1080/10503300802621206

Hill, C. E., Sim, W., Spangler, P., Stahl, J., Sullivan, C., \& Teyber, E. (2008). Therapist immediacy in brief psychotherapy: Case study II. Psychotherapy: Theory, Research, Practice, Training, 45, 298-315. doi: 10.1037/a0013306

Hill, C. E., Thames, T. B., \& Rardin, D. K. (1979). Comparison of Rogers, Perls, and Ellis on the Hill Counselor Verbal Response Category System. Journal of Counseling Psychology, 26, 198-203. doi: 10.1037/0022-0167.26.3.198

Hill, C. E., Thompson, B. J., \& Williams, E. N. (1997). A guide to conducting consensual qualitative research. The Counseling Psychologist, 25, 517-572. doi:10.1177/0011000097254001

Hilsenroth, M. J., Blagys, M. D., Ackerman, S. J., Bonge, D. R., \& Blais, M. A. (2005). Measuring psychodynamic-interpersonal and cognitive-behavioral techniques: Development of the Comparative Psychotherapy Process Scale. Psychotherapy: Theory, Research, Practice, and Training, 42, 340-356. doi: 10.1037/0033-3204.42.3.340

Hofmeister, B., (2010). The person-centered approach in Germany: To cut a long story short. Person-Centered and Experiential Psychotherapies, 9, 1-13. doi: 1477-9757/10/0100

Hunsley, J., \& Di Giulio, G. (2002). Dodo bird, phoenix, or urban legend? The question of psychotherapy equivalence. The Scientific Review of Mental Health Practice, 1(1). Online journal accessed at: www.srmhp.org/0101/psychotherapy-equivalence.html

Imel, Z. E., Steyvers, M., \& Atkins, D. C. (submitted). Computational psychotherapy: Scaling up the evaluation of patient provider interactions. Manuscript submitted for publication.

Ivey, A. E. (1971). Microcounseling: Innovations in interviewing training. Springfield, IL: Charles C. Thomas.

Jackson, J., Chui, H., \& Hill, C. E. (2012). The modification of CQR for case study research: An introduction to CQR-C. In C. E. Hill (Ed.), Consensual qualitative research: A practical resource for investigating social science phenomena (pp. 285-303). Washington DC: American Psychological Association.

Jones, E. E., \& Pulos, S. M. (1993). Comparing the process in psychodynamic and cognitivebehavioral therapies. Journal of Consulting and Clinical Psychology, 61(2), 306-316. doi: 10.1037/0022-006x.61.2.306

Kasper, L., Hill, C. E., \& Kivlighan, D. (2008). Therapist immediacy in brief psychotherapy: Case study I. Psychotherapy: Theory, Research, Practice, Training, 45, 281-287. doi: 10.1037/a0013305

Keefe, J.R., McCarthy, K.S., Dinger, U., Zilcha-Mano, S., \& Barber, J.P. (2014). A metaanalytic review of psychodynamic therapies for anxiety disorders. Clinical Psychology Review, 34, 309-323. DOI: 10.1016/j.cpr.2014.03.004

Kenny, D.A., \& Hoyt, W.T. (2009). Multiple levels of analysis in psychotherapy research. 
Psychotherapy Research, 19, 462-468. doi: 10.1080/10503300902806681

Kuhn, T. S. (1970). The structure of scientific revolutions. Chicago: University of Chicago Press.

Levins, R. (1968). Evolution in changing environments: Some theoretical explorations. Princeton, NJ: Princeton University Press.

Lambert, M. J. (2013). The efficacy and effectiveness of psychotherapy. In M. J. Lambert (Editor) Bergin \& Garfield's Handbook of Psychotherapy and Behavior Change $\left(6^{\text {th }}\right.$ Ed., Pp. 169-218). New York: Wiley.

Leichsenring F, Salzer S, Beutel ME, Herpertz S, Hiller W, Hoyer J, Huesing J, Joraschky P, Nolting B, Poehlmann K, Ritter V, Stangier U, Strauss B, Stuhldreher N, Tefikow S, Teismann T, Willutzki U, Wiltink J, \& Leibing E. (2013). Psychodynamic therapy and cognitive-behavioral therapy in social anxiety disorder: a multicenter randomized controlled trial. American Journal of Psychiatry, 170, 759-767. doi: 10.1176/appi.ajp.2013.12081125.

Leiman, M., \& Stiles, W. B. (2001). Dialogical sequence analysis and the zone of proximal development as conceptual enhancements to the assimilation model: The case of Jan revisited. Psychotherapy Research, 11, 311-330. doi: 10.1080/713663986

Lilienfeld, S.O. (2007). Psychological treatments that cause harm. Perspectives on Psychological Science, 2, 53-70. doi: 10.1111/j.1745-6916.2007.00029.x

Luborsky, L., Singer, B., \& Luborsky, L. (1975). Comparative studies of psychotherapies: Is it true that "Everyone has won and all must have prizes"? Archives of General Psychiatry, 32, 995-1008. doi:10.1001/archpsyc.1975.01760260059004.

Luborsky, L., Diguer, L., Seligman, D.A., Rosenthal, R., Krause, E.D., Johnson, S., Halperin, G., Bishop, M., Berman, J.S., \& Schweizer, E. (1999). The researcher's own therapy allegiances: A "wild card" in comparisons of treatment efficacy. Clinical Psychology,: Science and Practice, 6, 95- 106.

Luborsky, L., Rosenthal R., Diguer L., Andrusyna T.P., Berman J.S., Levitt J.T., Seligman D.A. \& Krause E.D. (2002). The Dodo bird verdict is alive and well - mostly. Clinical Psychology: Science and Practice, 9, 2-12.

MacLeod, R., \& Elliott, R. (2012). Emotion-focused therapy for social anxiety: A hermeneutic single-case efficacy design study of a low-outcome case. Counselling Psychology Review, 27: 7-22.

MacLeod, R., Elliott, R., \& Rodgers, B. (2012). Process-experiential/emotion-focused therapy for social anxiety: A hermeneutic single-case efficacy design study. Psychotherapy Research, 22, 67-81. doi:10.1080/10503307.2011.626805

Mahrer, A. R. (Chair) (1980, September). Psychotherapy process research: A preview of the next decade. Symposium presented at the American Psychological Association Convention, Montreal, Quebec, Canada.

McLeod, J. (2010). Case study research in counselling and psychotherapy. London: Sage.

Moher, D, Liberati, A, Tetzlaff, J, Altman, DG, \& The PRISMA Group. (2009). Preferred Reporting Items for Systematic Reviews and Meta-Analyses: The PRISMA Statement. PLoS Medicine 6(6): e1000097. doi:10.1371/journal.pmed1000097

Murphy, D. (2013). BAPCA Practice Research Network. Access on-line at: http://www.bapca.org.uk/blog/538-bapca-practice-research-network.html

National Collaborating Centre for Mental Health (2009). Depression: the treatment and management of depression in adults (update) (NICE clinical guideline 90). London: National Institute for Clinical Excellence. Available from www.nice.org.uk/CG90 
National Collaborating Centre for Mental Health (2010). Schizophrenia: The NICE guideline on core interventions in the treatment and management of schizophrenia in adults in primary and secondary care (Updated edition). London: National Institute for Clinical Excellence. Available at www.nice.org.uk/CG82

Nezu AM, Nezu CM. Evidence-based outcome research: a practical guide to conducting randomized controlled trials for psychosocial interventions. Oxford: Oxford University Press, 2008. ISBN 978-0-19-530463-3.

Norcross, J. (ed.) (2011). Psychotherapy relationships that work (2nd ed.). New York: Oxford University Press.

Orlinsky, D. E., Grawe, K., \& Parks, B. K. (1994). Process and outcome in psychotherapy Noch einmal. In A. E. Bergin \& S. L. Garfield (Eds.), Handbook of psychotherapy and behavior change, 4th ed. (pp. 270-376). New York: Wiley.

Peräkylä, A, Antaki. C, Vehviläinen, S \& Leudar, I (eds.) (2008) Conversation Analysis and Psychotherapy. Cambridge: Cambridge University Press.

Pinto-Coelho, K. G., \& Hill, C. E. (June, 2014). Characterizing therapist self-disclosure in psychodynamic psychotherapy. Paper presented at the Society for Psychotherapy Research, Copenhagen, Denmark.

Porter, E. H. Jr. (1943). The development and evaluation of a measure of counseling interview procedures. Educational and Psychological Measurement, 3, 105-126. doi: $10.1177 / 001316444300300111$

Rennie, D. L. (2000). Grounded theory methodology as methodological hermeneutics: Reconciling realism and relativism. Theory \& Psychology, 10, 481-502. doi: $10.1177 / 0959354300104003$

Rennie, D. L. (2004) Anglo-North American qualitative counseling and psychotherapy research, Psychotherapy Research. 14, 37-55. doi: 10.1093/ptr/kph003

Rennie, D.L., Phillips, J.R., \& Quartaro, G.K. (1988). Grounded theory: A promising approach to conceptualization in psychology? Canadian Psychology, 29, 139-150. doi: $10.1037 / \mathrm{h} 0079765$

Robinson, L. A., Berman, J. S., \& Neimeyer, R. A. (1990). Psychotherapy for the treatment of depression: A comprehensive review of controlled outcome research. Psychological Bulletin, 108, 30-49.

Rogers, C. R. (1942a). Counseling and psychotherapy. Boston: Houghton Mifflin.

Rogers, C. R. (1942b). The use of electrically recorded interviews in improving psychotherapeutic techniques. American Journal of Orthopsychiatry, 12, 429-434. doi: 10.1111/j.1939-0025.1942.tb05930.x

Rosenzweig, S. (1936). Some implicit common factors in diverse methods of psychotherapy. American Journal of Orthopsychiatry, 6, 412-415. doi: 10.1111/j.19390025.1936.tb05248.x

Safran, J.D., \& Muran, J.C. (2000). Negotiating the therapeutic alliance: A relational treatment guide. New York: Guilford.

Safran, J. D., Muran, J. C., \& Eubanks-Carter, C. (2011), Repairing alliance ruptures. Psychotherapy, 48, 80-87. doi: 10.1037/a0022140

Sales, C.M.D., \& Alves, P.C.G. (2012). Individualized patient-progress systems: Why we need to move towards a personalized evaluation of psychological treatments. Canadian Psychology/Psychologie canadienne, 53, 115-121. doi: 10.1037/a0028053

Snyder, W.U. (1945). An investigation of the nature of nondirective psychotherapy. Journal of 
General Psychology, 33, 193-223.

Society for Clinical Psychology. (2014). Website on research-supported psychological treatments. Access at: http://www.psychologicaltreatments.org/

Spielmans, G. I., Pasek, L. F., \& McFall, J. P. (2007). What are the active ingredients in cognitive and behavioral psychotherapy for anxious and depressed children? A metaanalytic review. Clinical Psychology Review, 27, 642-654. doi: 10.1016/06.001

Stephen, S., Elliott, R., \& MacLeod, R. (2011). Person-centred therapy with a client experiencing social anxiety difficulties: a hermeneutic single case efficacy design. Counselling and Psychotherapy Research, 11, 55-66. doi: 10.1080/14733145.2011.546203.

Stiles, W. B. (1979). Verbal response modes and psychotherapeutic technique. Psychiatry, 42, 49-62.

Stiles, W. B. (1993). Quality control in qualitative research. Clinical Psychology Review, 13, 593-618. http://dx.doi.org/10.1016/0272-7358(93)90048-Q

Stiles, W. B. (2002). Assimilation of problematic experiences. In J. C. Norcross (Ed.), Psychotherapy relationships that work: Therapist contributions and responsiveness to patients (pp. 357-365). New York: Oxford University Press.

Stiles, W. B. (2009). Logical operations in theory-building case studies. Pragmatic Case Studies in Psychotherapy, 5(3), 9-22. Available: http://jrul.libraries.rutgers.edu/index.php/pcsp/article/view/973/2384

Stiles, W. B. (2011). Coming to terms. Psychotherapy Research, 21, 367-384. doi: 10.1080/10503307.2011.582186

Stiles, W. B. (in press). Theory-building, enriching, and fact-gathering: Alternative purposes of psychotherapy research. In O. Gelo, A. Pritz, \& B. Rieken (Eds.), Psychotherapy research: General issues, process, and outcome. New York: Springer-Verlag.

Stiles, W. B., Barkham, M., Mellor-Clark, J., \& Connell, J. (2008). Routine psychological treatment and the Dodo verdict: A rejoinder to Clark et al. (2007). Psychological Medicine, 38, 905-910. Published online 08 February 2008, doi: 10.1017/S0033291708002717.

Stiles, W. B., Elliott, R., Llewelyn, S. P., Firth-Cozens, J. A., Margison, F. R., Shapiro, D. A., \& Hardy, G. (1990). Assimilation of problematic experiences by clients in psychotherapy. Psychotherapy, 27, 411-420. doi: 10.1037/0033-3204.27.3.411

Stiles, W. B., Honos-Webb, L., \& Surko, M. (1998). Responsiveness in psychotherapy. Clinical Psychology: Science and Practice, 5, 439-458. doi: 10.1111/j.1468-2850.1998.tb00166.x

Stiles, W. B., Meshot, C. M., Anderson, T. M., \& Sloan, W. W., Jr. (1992). Assimilation of problematic experiences: The case of John Jones. Psychotherapy Research, 2, 81-101. doi: 10.1080/10503309212331332874

Stiles, W. B., \& Shapiro, D. A. (1994). Disabuse of the drug metaphor: Psychotherapy processoutcome correlations. Journal of Consulting and Clinical Psychology, 62, 942-948. doi: 10.1037/0022-006X.62.5.942

Stiles, W. B., Shapiro, D. A., \& Elliott, R. (1986). "Are all psychotherapies equivalent?" American Psychologist, 41, 165-180. doi: 10.1037/0003-066X.41.2.165

Stiles, W. B., Shapiro, D. A., \& Firth-Cozens, J. A. (1988). Verbal response mode use in contrasting psychotherapies: A within-subjects comparison. Journal of Consulting and Clinical Psychology, 56, 727-733. doi: 10.1037/0022-006X.56.5.727

Stiles, W. B., \& Sultan, F. E. (1979). Verbal response mode use by clients in psychotherapy. 
Journal of Consulting and Clinical Psychology, 47, 611-613.

Sutherland, O., Peräkylä, A., \& Elliott, R. (2014). Conversation analysis of the two chair selfsoothing task in emotion-focused therapy. Psychotherapy Research. Advance online publication. doi: 10.1080/10503307.2014.885146

Timulak, L. (2007). Identifying core categories of client-identified impact of helpful events in psychotherapy: A qualitative meta-analysis. Psychotherapy Research, 17. 305-314.

Torgerson D. J., Torgerson C. Designing randomised trials in health, education and the social sciences: an introduction. Basingstoke, England, and New York: Palgrave Macmillan, 2008. ISBN 978-0-230-53735-4.

Tolin, D. F. (2010). Is cognitive-behavioral therapy more effective than other therapies?: A meta-analytic review. Clinical Psychology Review, 30, 710-720.

Vromans, L.P., \& Schweitzer R.D. (2011). Narrative therapy for adults with major depressive disorder: improved symptom and interpersonal outcomes. Psychotherapy Research, 21, 4-15. doi: 10.1080/10503301003591792.

Wampold, B. E. (2001). The great psychotherapy debate: Models, methods, and findings. Mahwah, NJ: Lawrence Erlbaum Associates.

Wasserman, R.H., Levy, K.N., \& Loken, E. (2009). Generalizability theory in psychotherapy research: The impact of multiple sources of variance on the dependability of psychotherapy process ratings. Psychotherapy Research, 19, 397-408. doi: $10.1080 / 10503300802579156$

\section{Footnote}

1. Alvin R. Mahrer died April 13, 2014, in Ottawa, as we were putting the finishing touches on this manuscript. 